\title{
Challenges confront the California family
}

$\mathrm{H}$ ow well does California treat its children? Children Now gave the state either a " $\mathrm{D}$ " or a "D-" for its efforts in the years 1989 to 1992 . Last year, the national advocacy group did not give letter grades, but disclosed disturbing facts in its most recent report California: The State of Our Children 1993. For instance, when compared to other states, California's children are:

- more likely to grow up poor;

- less likely to have health insurance;

- less likely to receive child support;

- more likely to have babies as teenagers;

- less likely to go to college;

- more likely to be unemployed; and

- more likely to be victims of homicide.

Can a state's future be foretold by the way it treats its children? Advocacy organizations say "yes." If they are right, California has witnessed foreboding changes in the last 20 years; some of them, including a $50 \%$ rise in poverty, increases in divorce and the number of single parents, mirror national trends. Others, such as the dramatic shifts in California's racial and ethnic composition, are unique to the state. In part due to economic stress and the breakup of the family, Children Now reports that the state has witnessed "alarming declines" in its efforts to contain such rising problems as child abuse, up $41 \%$ between 1988 and 1991; juvenile homicide, up 59\%; and teen births, which rose $23 \%$ during the same 4-year period.

Although it's difficult to draw conclusions about exact cause and effect, a large body of evidence points to one unfortunate result: When problems like hunger and poverty occur early in life, they cause a cascade of effects that touch all Californians for years to come.

One of the most dramatic changes in the state has been its increasing ethnic diversity; the white population is projected to be a minority by the year 2000. More than half of California's schoolchildren are minorities, and one in five California schoolchildren has only limited English proficiency, according to recent studies.

Statistics show that minorities are disproportionately affected by poverty and its associated problems. For instance, the 1993 Current Population Survey Report shows a $16 \%$ poverty rate for

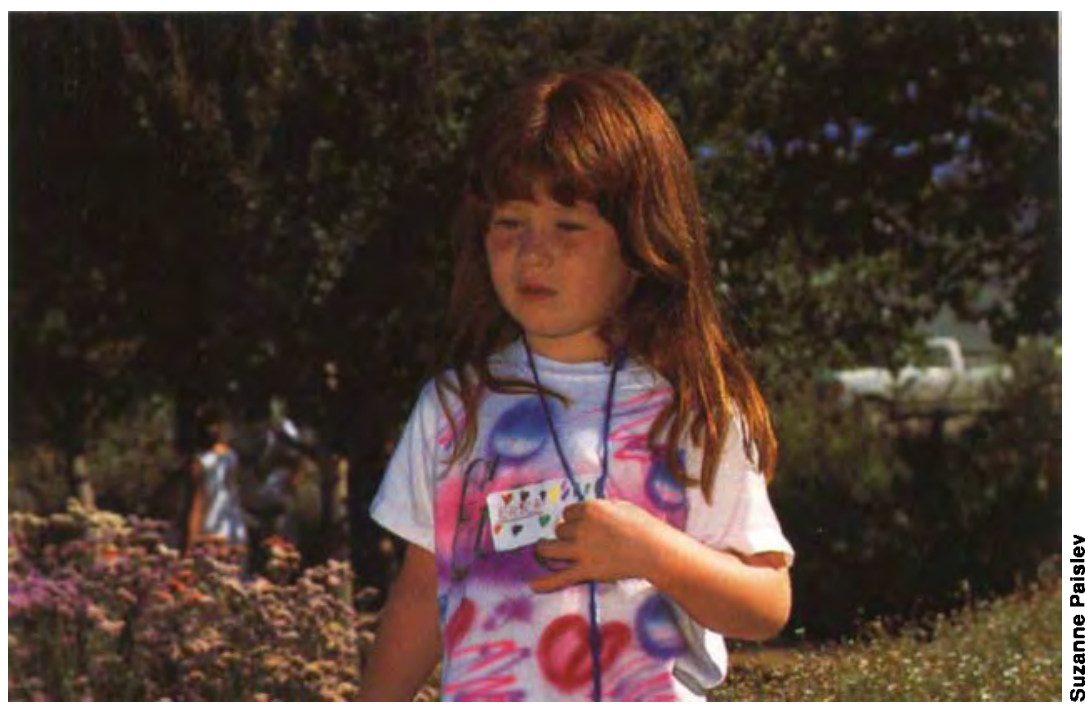

the state as a whole. However, among Hispanics the rate was $28 \%$; among African-Americans, $25.4 \%$ and among whites, $9.5 \%$.

Although the majority of California children continue to live with two-parent families, the families may be reconstituted with stepparents and stepsiblings. More than half of all California children will spend at least a portion of their childhood in a single parent home, according to Children Now. UC studies show $24 \%$ of all California mothers are unmarried, and some $60 \%$ of children come from divorced or single-parent homes.

By contrast, more than $80 \%$ of children in the postwar generation grew up in an intact family with two biological parents, according to writer Mary Beth Whitehead in an extensive review of the single-parent family which appeared in the Atlantic Monthly in April 1993.

A constellation of problems surrounds single parenthood and especially single motherhood. Half the single mothers in the United States live below the poverty line, with income declining an average of $30 \%$ for women after divorce. This statistic holds true for California, where $57 \%$ of all female-headed households with children lived in poverty in
In California, 1 out of every 4 children lives in poverty, a statistic that has implications for all Californians.

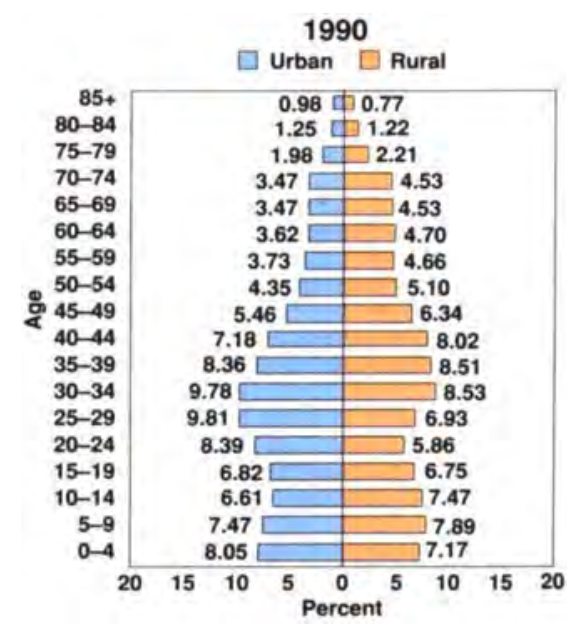

The age distributions of both rural and urban Californians are pictured above. Both rural and urban areas show bulges for the very young, ages 0-4, and in the 20 to 40 -year-old range. 
HOUSEHOLDS WITH CHILDREN
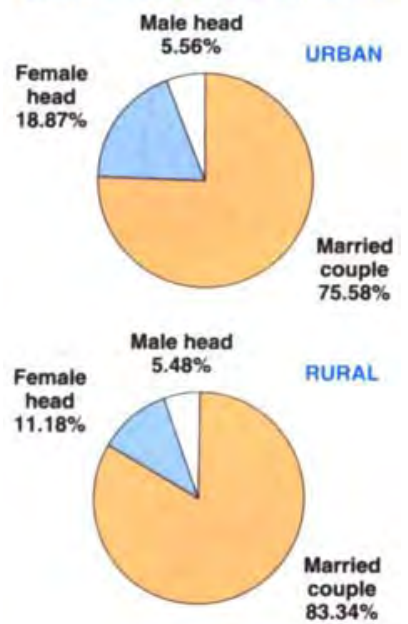

Although the majority of California children still live in two-parent homes, single-parent households, particularly those headed by women, are increasing in both urban and rural areas.
1990 , according to census figures. Partly as a result of this, one-fourth of California's children now live in poverty, significantly more than the $15 \%$ who did so in 1980 , according to Children Now.

If present trends continue, fully one-third of California's child population will live in poverty by the year 2000, advocacy officials predict.

Child poverty is an important indicator of child well-being. Poor children are four times as likely to die in infancy. They are also more likely to suffer serious illness, drop out of school or become pregnant as teenagers.

As noted elsewhere in this issue, (see page 11) about $13 \%$ of California's population is hungry, which puts the state among the top 15 with the largest hungry populations. Almost one-third of all school children in the state receive free or reduced-price lunches.

While it is difficult to point to any one cause for California's ills, research suggests that in addition to economic stress, the breakup of the family may be at the root of such problems as poverty, high school dropout rates and even increases in violent juvenile crime.

In her 1993 review of the single-parent family, Whitehead reported that children in singleparent families are six times more likely to be poor as children Urban $\square$ Rural

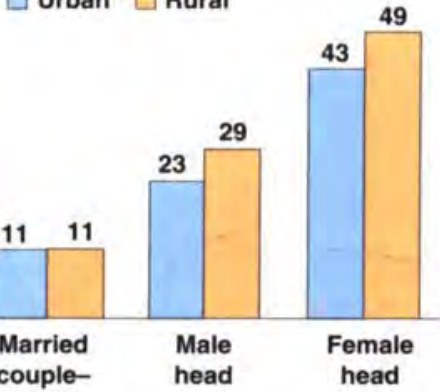
from two-parent families. They are also more likely to drop out of high school, get pregnant as teenagers, abuse drugs and get in trouble with the law. Nationwide, over $70 \%$ of all juveniles in state reform institutions come from fatherless homes.

Children from single-parent families usually do not receive the financial support of two parents. Nearly one-third of all California babies are born to unmarried parents, and many custodial parents

Among families with children, women with children comprise the fastest growing segment of the state's poor. Percentages have been rounded. do not seek or receive court-ordered child support. In 1994, less than half ( $40 \%$ ) of children with court-ordered child support received even partial payment.

Economic instability can lead to many other problems, not the least of which are the emotional adjustments that may be required of children forced to move to a new home, form new attachments with a stepparent or lose contact with the noncustodial parent. One study showed that 10 years after a marriage breaks up, more than two- thirds of children report not having seen their father for a year.

Children in disrupted families face a myriad of other problems. They are nearly twice as likely to drop out of high school. One study which focused on white families found that daughters of single parents are not only more likely to divorce, they're also more likely to marry or have children as teenagers. Fewer children from disrupted families attend college.

California's family portrait mirrors many of these national trends. In its 1993 report, Children Now examined 27 benchmarks, which taken together provide a statistical profile of the California child.

There were some reasons for hope - most noticeably, a $13 \%$ decrease in the number of infant deaths between 1988 to 1992 , and a decrease in the number of students who dropped out of high school. That number, which had been $18.2 \%$ in $1990-91$, dropped to $16.6 \%$ in 1991-92.

But there were reasons for concern as well, with increases reported in such areas as child abuse and neglect, teenage arrests for felony crime, teen homicides and teenagers giving birth.

For instance, in 1992 the number of reported cases of child abuse and neglect was almost double the number of reported violent crimes such as rape, murder and assault. Child abuse reports increased $41 \%$ between 1988 and 1991 - to more than double the incidents reported in 1984.

Teen crime and homicide also increased. According to Children Now, 828 teenagers were murdered in California in 1992, a 59\% increase from just 4 years earlier - almost two teenagers killed per day.

Although crime often is associated with big cities, Children Now found that predominantly rural counties logged the highest rates of juvenile felony arrests. Overall, juvenile incarceration rates rose $23 \%$ between 1988 and 1991, climbing to 256 arrests every day.

More than 70,000 babies - or 1 in 8 - are born to teenagers in California every year, according to statistics. Although the numbers fluctuate, California's rate of teen births is higher than the national average, with teen mothers accounting for $11 \%$ of all mothers in the state, according to Children Now.

Education statistics were not much more optimistic. According to a 1992 report issued by the Policy Analysis for California Education (PACE), 
a university-based research center, the state spends less per pupil than any other industrialized state. Class size in California is second highest in the nation, after Utah.

The report noted that California gains an average of 150,000 new students a year. In 1991-92, California's public schools enrolled more than 5 million students, 1 million more than the combined enrollments of Colorado, Florida, Minnesota and Maryland. California has more students in its $K-6$ system than New York has in its entire K-12 system. Private schools account for nearly $10 \%$ of the school-age population

The PACE report found that academically, California students are not doing as well as they once did. While the high school dropout rate improved, there were continued gaps in achievement between racial and ethnic groups, with African-Americans and Latinos scoring substantially lower in the California Assessment Program tests - particularly in reading.

In 1960, according to the Center on Budget and Policy Priorities, a Washington, D.C. thinktank, California spent $21 \%$ more per student than the rest of the nation. Now, it spends $14 \%$ less than the national average.

With statistics such as these, it's hard to know what to be optimistic about as the International Year of the Family ends. But even officials of advocacy organizations, who make a point of assessing what's wrong in order to improve it, see room for hope.

"There's a lot of hope and there are a lot of examples of good efforts that are happening around the state," said Amy Abraham, acting policy director for Children Now. These include efforts described in this issue, as well as other government programs and community attempts to solve such problems as teenagers giving birth, or fathers failing to provide child support.

Among programs Children Now cited in its 1993 report were "Healthy Tomorrow," a Contra Costa County program designed to improve the health of pregnant women and infants, with special emphasis on African-Americans. Outreach workers visited soup kitchens, shelters and other facilities to find pregnant women and link them with health care. They provided transportation to health care programs along with improved health care, education and nutrition information. As a result, the county now has the lowest infant mortality rate for African-Americans and has already reached its target goal for the year 2000 .

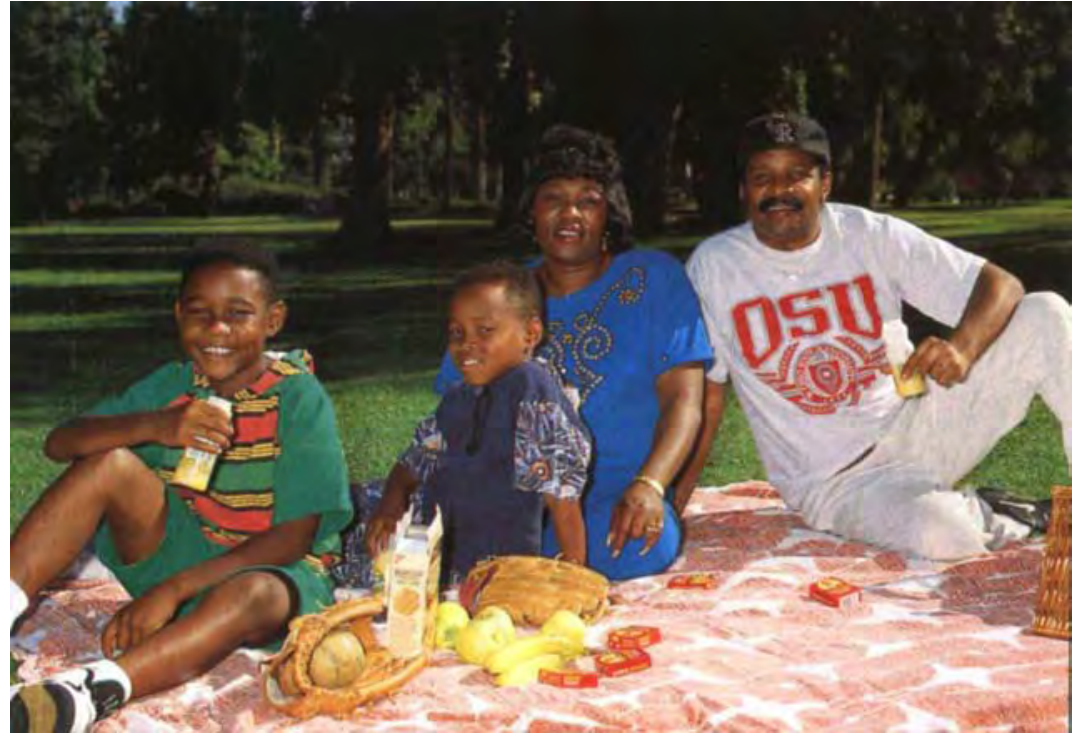

Hope for the California family rests in part with communities themselves, which have taken the initiative to develop programs targeting such areas as educational achievement, teen parenting and prenatal care.

The issue of child support is highlighted in a California Department of Social Services program to educate kids about the child support system. "What Kind of Parent Will You Be?" is a curriculum designed for 9th through 12th graders, to help them understand the emotional and financial responsibilities of being a parent. The program is included in Los

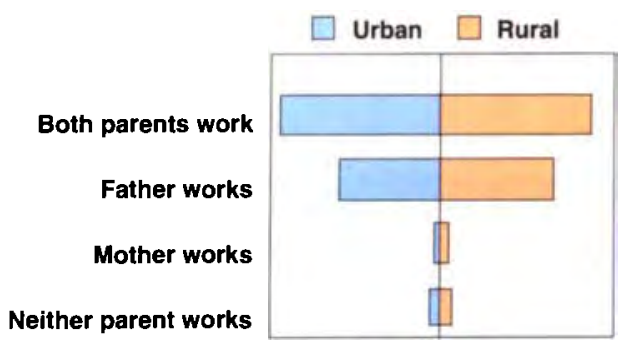

6050403020100102030405060 Percent

Angeles Unified School

District's curriculum, and is taught in many other California high schools. A second program, called the Parent Opportunity Program, allows natural parents of a child to acknowledge paternity by simply signing a declaration at the birth site, cutting down on court time and making it more likely that both parents will be involved and honor their obligations. Governor Wilson has signed legislation ensuring this program will be expanded statewide by January 1995.

In an effort to improve the educational achievement of all kids, not just the academically advanced, several San Jose schools have adopted the Accelerated Schools Project, which challenges conventional wisdom about

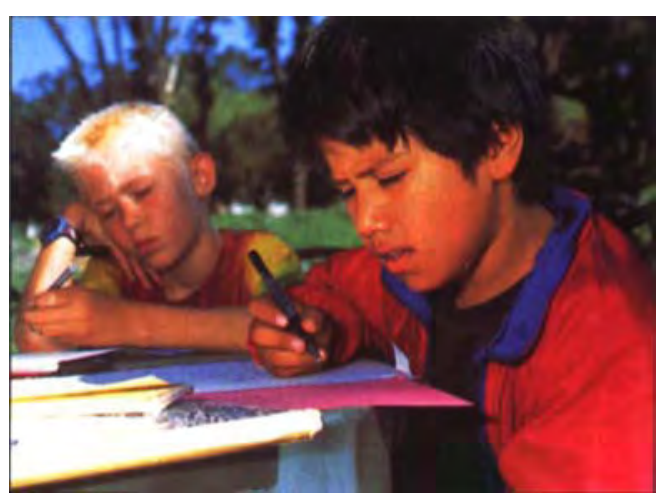

Class size in California is second highest in the nation, after Utah.
The figure above shows the number of working parents in two-parent homes. The majority of children come from homes where both parents work. 
